Research

\title{
Comparing electrochemical analysis and particle induced X-ray emission measurements of Prussian Blue Analogue deposits
}

\author{
Scott D. Joffre ${ }^{1,2} \cdot$ Paul A. DeYoung ${ }^{1} \cdot$ Jennifer R. Hampton ${ }^{1}$
}

Received: 4 January 2021 / Accepted: 19 April 2021

Published online: 10 May 2021

(c) The Author(s) $2021 \quad$ OPEN

\begin{abstract}
Prussian Blue Analogues are of major interest for their use in alternative battery technologies due to their charge storing ability with a long life cycle. In this work the Prussian Blue Analogue nickel hexacyanoferrate (Ni-HCF) was produced using an all electrochemical method. Creating charge storing materials with electrochemical processes provides a new approach to the development of battery-like materials. These methods have not been commonly employed because the charge storing material yield is not directly known. The charge storage of the Ni-HCF was characterized with two different methods which provided a measure of the electrochemically active Fe present. These were then compared with the Particle Induced X-ray Emission (PIXE) method which measured the total amount of Fe present. By comparing the electrochemical measurement of active Fe to the total Fe as measured by PIXE, the percentage of material that is active in the charge storage was determined. This enables an independent calculation of the specific charge capacity of the material for comparison to other battery technologies.
\end{abstract}

Keywords Prussian Blue Analogues · Particle Induced X-ray Emission · Batteries · Energy storage · Electroformation · Specific charge capacity

$\begin{array}{ll}\text { Abbreviations } \\ \text { CA } & \text { Chronoamperometry } \\ \text { CV } & \text { Cyclic Voltammetry } \\ \text { EDS } & \text { Energy-Dispersive X-ray Spectroscopy } \\ \text { HIBAL } & \text { Hope lon Beam Analysis Laboratory } \\ \text { Ni-HCF } & \text { Nickel hexacyanoferrate } \\ \text { PBA } & \text { Prussian Blue Analogue } \\ \text { PIXE } & \text { Particle Induced X-ray Emission } \\ \text { SEM } & \text { Scanning Electron Microscope }\end{array}$

Supplementary Information The online version contains supplementary material available at https://doi.org/10.1007/s43939-02100013-z.

Scott D. Joffre, sjoffre@g.clemson.edu; Paul A. DeYoung, deyoung@hope.edu; Jennifer R. Hampton, hampton@hope.edu| ${ }^{\text {Physics }}$ Department, Hope College, 49423 Holland, MI, USA. ${ }^{2}$ Present Address: Department of Physics \& Astronomy, Clemson University, 29634 Clemson, SC, USA. 


\section{Introduction}

Due to the intermittency of common green energy sources such as solar and wind, large scale batteries that can store this energy are of great importance for pursuing practical applications. Open-framework materials such as the Prussian Blue Analogues (PBAs) are a promising avenue of investigation to help meet these challenges for growing energy storage needs [1-9]. The open crystalline structure of PBAs allows for charge storage without large volume changes [10-14]. Additionally, the composition of PBAs is modifiable, enabling both tuning of the resulting properties and the use of earth abundant elements that make it a more sustainable battery alternative [15-20]. Most literature on the fabrication and study of these materials is based on nanoparticle techniques [21-30]. In contrast, with an electrochemical method described by Bocarsly and coworkers, the material can be produced directly on an electrode instead of requiring an additional step to bind the material to the electrode [31-39].

A downside to this all electrochemical method is that the measurement of the amount of material produced is indirect. Electrochemical techniques such as Cyclic Voltammetry (CV) can be used to measure the amount of active material in a sample. However, in order to compare charge efficiency to other battery technologies, it is important to have an independent measurement of the amount of material so that a specific charge capacity (in units of $\mathrm{mAh} / \mathrm{g}$, for example) can be calculated.

One method to obtain an absolute measurement of material in a thin film sample is Particle Induced X-ray Emission (PIXE) [40]. PIXE is a non-destructive materials characterization technique that can determine the type and amount of elements present in a sample independent of any electrochemical measurements. In PIXE, protons are passed through a material exciting inner shell electrons. Characteristic X-rays are emitted upon the return of electrons to lower energy states. The spectrum of emitted X-rays is analyzed to determine the absolute areal densities of the elements present. This method is particularly sensitive for measuring heavier elements such as transition metals because of the higher excitation energy compared to Energy-Dispersive X-ray Spectroscopy (EDS) using a Scanning Electron Microscope (SEM). In addition, the penetration depth for this technique is typically higher than that for EDS, which decreases measurement variability due to inhomogeneity in surface morphology or composition.

In this work, the PBA nickel hexacyanoferrate (Ni-HCF) was produced using an all electrochemical process. Ni-HCF is a promising candidate for this process as the two step method of deposition followed by a modification works particularly well in the case of $\mathrm{Ni}$. The specific charge capacity of the material was determined by comparison of the Fe areal density found with PIXE to the active areal density of Fe measured with CV. This can then be compared directly to various other current battery technologies to further evaluate the effectiveness of the specific PBA for battery applications.

This paper verifies this methodology as a viable way to compare Ni-HCF and other PBAs directly to other battery technologies. Lastly, this paper describes evidence discovered during the development of these methods for the presence of additional reactions. Additional study of the reactions taking place in the charging and discharging of $\mathrm{Ni}-\mathrm{HCF}$ is necessary to better understand this interesting battery alternative.

\section{Methods}

\subsection{Sample setup, preparation, and geometry}

All electrochemical experiments were done with a BAS Epsilon (Bioanalytical Systems, Inc., West Lafayette, IN, USA) or a Gamry Interface 1000 (Gamry Instruments, Warminster, PA, USA) electrochemical workstation. The substrates

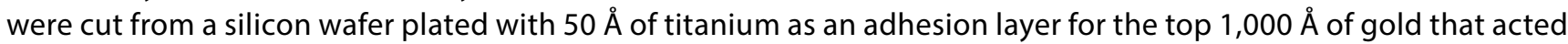
as the working electrode (Platypus Technologies, LLC, Madison, WI, USA). A coiled platinum wire (Alfa Aesar, Ward Hill, MA, USA) acted as the counter electrode, and the reference electrode was a $\mathrm{Ag} / \mathrm{AgCl}(3 \mathrm{M} \mathrm{NaCl})$ from Bioanalytical Systems, Inc., (West Lafayette, IN, USA). All potentials in solutions are reported with respect to the reference electrode. A custom-built Teflon cell [41] was used as a platform for sample fabrication. The Teflon cell limits the geometric area of the working electrode to be $0.032 \pm 0.005 \mathrm{~cm}^{2}$. All chemicals were purchased from Sigma-Aldrich (St. Louis, MO, USA) and used as received. All solutions were made using $18 \mathrm{M} \Omega \cdot \mathrm{cm}$ water purified with a Barnstead Nanopure Infinity system (APS Water Services Corp., Van Nuys, CA, USA). Solutions were purged for $10 \mathrm{~s}$ with purified 
$\mathrm{N}_{2}$ (99.999\% Nitrogen, Airgas an Air Liquid Company, Radnor Township, PA, USA) and then blanketed with the gas for the rest of the experiment. In order to minimize cross contamination between solutions, the electrodes and Teflon cell were rinsed thoroughly with the $18 \mathrm{M} \Omega \cdot \mathrm{cm}$ water and dried with Light-Duty Tissue Wipers (VWF International, Radnor PA, USA) between each different solution.

\subsection{Film fabrication}

Fabrication of the Ni-HCF films included both an electrochemical deposition step and an electrochemical modification step. Ni was first deposited onto Au with DC Potential Amperometry. The thin Ni films were deposited from $0.1 \mathrm{M} \mathrm{NiSO}_{4}$, $0.5 \mathrm{M} \mathrm{H}_{3} \mathrm{BO}_{3}$, and $1 \mathrm{M} \mathrm{Na}_{2} \mathrm{SO}_{4}$ aqueous solutions ( $\left.\mathrm{pH} \sim 4.6\right)$. The potential of the working electrode was stepped from an open circuit to $-1 \mathrm{~V}$ until 96 or $100 \mathrm{mC}$ of charge had passed. The modification process used Cyclic Voltammetry (CV) with an aqueous solution consisting of $0.01 \mathrm{M} \mathrm{K}_{3} \mathrm{Fe}(\mathrm{CN})_{6}$ and $1 \mathrm{M} \mathrm{NaNO}_{3}(\mathrm{pH} \sim 5.8)$. During modification, $\mathrm{CV}$ was used to measure current as the potential changed continuously from $0.800 \mathrm{~V}$ to $-0.200 \mathrm{~V}$ and back to $0.800 \mathrm{~V}$ at a scan rate of $0.050 \mathrm{~V} / \mathrm{s}$. Figure S1 in the Supplementary Information shows an example of the measured current during this step. The main features seen in the data are due to the redox behavior of the solution $\mathrm{Fe}(\mathrm{CN})_{6}^{3-/ 4-}$. Subtle shifts in the current and scan shapes between cycles, particularly around $0.4 \mathrm{~V}$, are indicative of the surface-bound Ni-HCF film. The $\mathrm{K}_{3} \mathrm{Fe}(\mathrm{CN})_{6}$ reacted with the already deposited $\mathrm{Ni}$ to fabricate the $\mathrm{Ni}-\mathrm{HCF}$, described by

$$
\begin{aligned}
{\left[\mathrm{Fe}^{\mathrm{III}}(\mathrm{CN}) 6\right]_{(\mathrm{aq})}^{3-}+\mathrm{Ni}_{(\mathrm{s})}+\mathrm{Na}_{(\mathrm{aq})}^{+} } & \longrightarrow\left[\mathrm{Fe}^{\mathrm{III}}(\mathrm{CN}) 6\right]_{(\mathrm{aq})}^{3-}+\mathrm{Ni}_{(\mathrm{aq})}^{2+}+\mathrm{Na}_{(\mathrm{aq})}^{+}+2 e^{-} \\
& \longrightarrow \mathrm{NaNi}^{\mathrm{II}}\left[\mathrm{Fe}^{\mathrm{III}}(\mathrm{CN}) 6\right]_{(\mathrm{s})}+2 e^{-}
\end{aligned}
$$

\subsection{Electrochemical sample characterization}

The newly fabricated Ni-HCF was tested in an aqueous $1 \mathrm{M} \mathrm{NaNO}_{3}$ solution ( $\mathrm{pH} \sim 5.5$ ) by $\mathrm{CV}$ and Chronoamperometry (CA). CV scans were done from $-0.200 \mathrm{~V}$ to $0.800 \mathrm{~V}$ at a variety of scan rates from $0.010 \mathrm{~V} / \mathrm{s}$ to $1.000 \mathrm{~V} / \mathrm{s}$. Figure 1 shows CV data for an example Ni-HCF film for several scan rates. Charge was calculated by integrating the current and subtracting the background for the scan from a drawn line. In some cases, especially at low scan rates, the sloped background current was significant. Figure $\mathrm{S} 2$ in the Supplementary Information shows example CV measurements on a Ni film that was not subjected to the modification step. A small featureless background is observed. Therefore, we attribute the larger background current seen in Fig. 1 to reactions that are separate from the PBA charge storage reaction, but that are enhanced due to the presence of the PBA. One possibility is reactions with water at lower potentials than observed on $\mathrm{Ni}$ alone. To account for this and focus solely on the $\mathrm{Fe}$, two points were selected that encompass the major peak of the Fe oxidation reaction, and a straight line was drawn between the two points, as seen in Fig. 1. Scan rates and scan ranges were chosen for analysis based on the ability to clearly determine the Fe peak from the background. The uncertainty of this background subtraction method was estimated by testing the

Fig. 1 Example CV scans of a Ni-HCF sample at 0.010 , 0.050 , and $0.180 \mathrm{~V} / \mathrm{s}$. The red dashed lines are the assumed background lines for the anodic scan. The charge was calculated for each scan rate by integrating the anodic peak above the background line and using Eq. 4

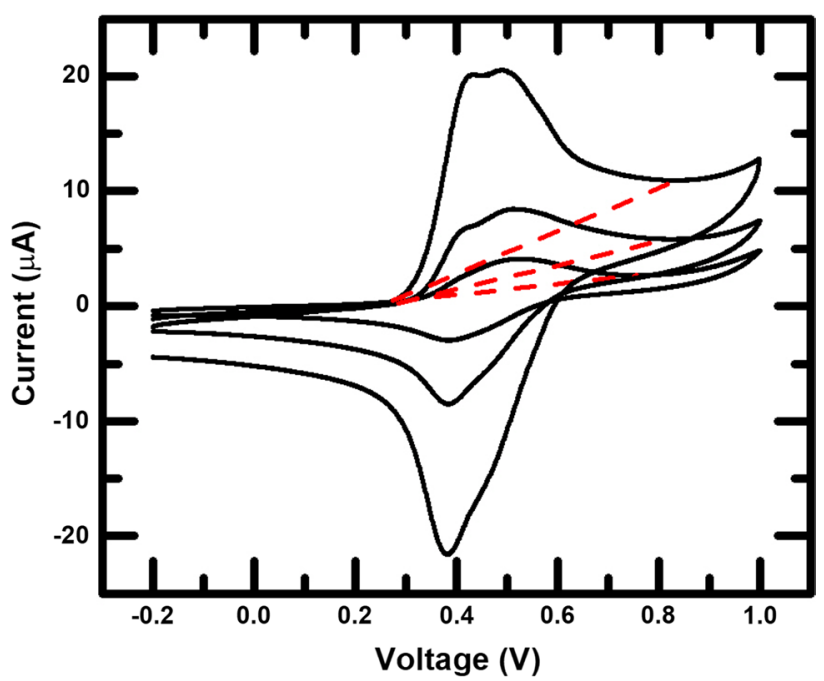


variation of results with differing endpoints. After multiple tests of multiple samples, it was found that for reasonable background selection, the uncertainty in the integrated charge was negligible compared to other uncertainties in the calculation of the areal density of Fe.

Total active atoms are more accurately measured by CV using a scan rate that is kept slow enough to capture the entire reaction. Therefore, most analysis was done with the slower scan rate of $0.010 \mathrm{~V} / \mathrm{s}$. This choice of scan rate was a trade off between being able to measure any slow kinetic processes and the practical consideration of observing the Fe peak clearly. If scan rates lower than $0.010 \mathrm{~V} / \mathrm{s}$ were used, the peak became difficult to distinguish clearly from the background.

The charge, $Q_{C V}$, was calculated by integrating the anodic current $i$, above the chosen background as a function of potential, $E$,

$$
Q_{C V}=\frac{1}{v} \int i(E) d E,
$$

where $v$ is the scan rate. From the integrated charge, the areal density of active $\mathrm{Fe}, \Gamma_{C V}$, was calculated with

$$
\Gamma_{C V}=\frac{Q_{C V}}{n e A},
$$

where $n=1$ is the number of electrons transferred per iron in the charge storage reaction, $e$ is the charge on the electron, and $A$ is the geometric area of the electrode.

All CA scans were stepped from $0.300 \mathrm{~V}$ to $0.800 \mathrm{~V}$ and back to $0.300 \mathrm{~V}$. Due to the instrument's inability to autoscale from the large current values at the beginning to the small current values that are present at a longer timescale, two different CA tests were done. The short timescale CA had a stepping time of $4 \mathrm{~s}$ at a sampling rate of $10,000 \mathrm{~Hz}$ and a current scale of $i_{\max }=100 \mathrm{~mA}$. The long timescale CA had a stepping time of $120 \mathrm{~s}$, a sampling rate that started at $10,000 \mathrm{~Hz}$ and was periodically decreased by factors of 10 until the rate reached $0.1 \mathrm{~Hz}$ with a current scale of $i_{\max }=1 \mathrm{~mA}$. The periodically changing sampling rate for the long timescale CA was chosen to reduce the large amount of data that would be collected over the entire $120 \mathrm{~s}$ at a constant $10,000 \mathrm{~Hz}$. The long and short timescale CA scans were combined together as seen in Fig. 2. The short timescale CA values were retained up until the current values measured by the long timescale CA scans stopped overloading. The charge, $Q_{C A}$, as a function of time was found by integrating the current for the forward step,

$$
Q_{C A}=\int i(t) d t
$$

Fig. 2 Example of the method for combining long and short timescale $C A$ raw data for a $\mathrm{Ni}-\mathrm{HCF}$ sample. The non-filled points are the ones that are removed. For early times, up until about $2 \mathrm{~ms}$, the long timescale current data is overloaded. The variation in the early portion of the short timescale data is noise and exists mainly when the time is less than $1 \mathrm{~ms}$

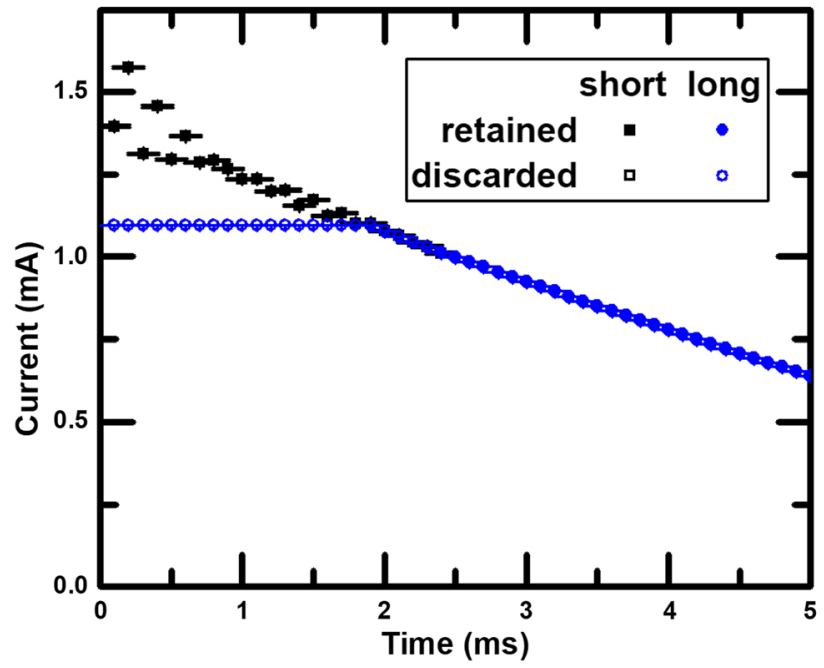


Repeated CV scans were performed after the CV measurements at various scan rates and after the CA measurements. An example is shown in Figure $\mathrm{S} 3$ in theSupplementary Information, which confirms reasonable stability of the samples during electrochemical testing.

\subsection{X-ray spectroscopic sample characterization}

PIXE measurements were taken using a National Electrostatics Corporation 1.7 MeV tandem Pelletron particle accelerator at the Hope College Ion Beam Analysis Laboratory (HIBAL). X-ray emission, measured with a XR-100SDD Silicon Drift Detector (Amptek Inc., Bedford, MA, USA) was induced by a beam of $3.4 \mathrm{MeV}$ protons with a beam current of $\sim 0.3-1.0 \mathrm{nA}$. Beam current was averaged from the electric current caused by the proton beam before and after the experimental run. Data collection was performed for $500 \mathrm{~s}$ or was terminated when the area under the Fe peak had reached 1,000 counts. A 5 mil Mylar film filter, placed between the target and detector, eliminated low energy X-rays and limited system deadtime. In order to obtain absolute measurements of the areal density of the elements present, the detector system was calibrated with an Fe Micromatter thin film standard (Micromatter Technologies Inc., Surrey, British Columbia, Canada). These calibration runs were done at a beam current of $\sim 0.5 \mathrm{nA}$ for $300 \mathrm{~s}$. The Micromatter standards are thin and beam particles have enough energy to pass through allowing the beam current to be measured simultaneously with data collection. Some samples were analyzed more than once in order to test the consistency of the technique and to investigate sample degradation. Others were measured at multiple locations of the same sample to detect consistency of the sample across the area. These results are in agreement with previous research for these type of materials [42].

An example PIXE spectrum of a Ni-HCF sample is seen in Fig. 3. The uncalibrated, relative areal densities for the elements present were extracted from the measured spectra with the computer program GUPIX developed by J. L. Campbell of University of Guelph [43]. Within GUPIX, the thick sample with surface elements option was selected due to the relative thinness of the PBA and the gold layers compared to the silicon of the wafer. A Si matrix element with surface fit elements of $\mathrm{Ni}-\mathrm{K}, \mathrm{Fe}-\mathrm{K}, \mathrm{Ti}-\mathrm{K}$, and $\mathrm{Au}-\mathrm{L} \mathrm{X}$-rays along with parameters that corresponded to the setup of the accelerator and detector were included in the model. From the fit, GUPIX calculated and then reported an areal density in units of $\mathrm{ng} / \mathrm{cm}^{2}$ for each element present in the sample. For the example shown in Fig. 3, the Ni:Fe ratio is approximately 1800:1. This is evidence that for these samples, only a small portion of the deposited Ni layer reacted to form Ni-HCF. In addition, a peak due to intercalated $\mathrm{Na}$ is not visible in the spectrum because the energy is too low for the detector/filter setup. These two observations together show that the stoichiometry of the reacted Ni-HCF film can not be determined from PIXE measurements.

Nevertheless, the PIXE measurements are useful to determine the total amount of Ni-HCF present. Fe is not present after the initial deposition step, and is only present after the modification step that forms the Ni-HCF film. Additionally, the iron sites in the crystalline structure are what undergoes charge exchange. Therefore, the primary values of interest from the GUPIX fits are the Fe results. The Fe values reported from the GUPIX fits of the emission spectra were converted to an areal density of $\mathrm{Fe}, \Gamma_{\mathrm{PIXE}}$, in atoms $/ \mathrm{cm}^{2}$ using the molar mass of $\mathrm{Fe}$. The absolute normalization of all measurements was based on regularly repeated measurements of the Micromatter standard.

Fig. 3 Example PIXE spectrum of a Ni-HCF sample. Ti-K, Ni-K, Fe-K, and Au-L X-ray lines are indicated

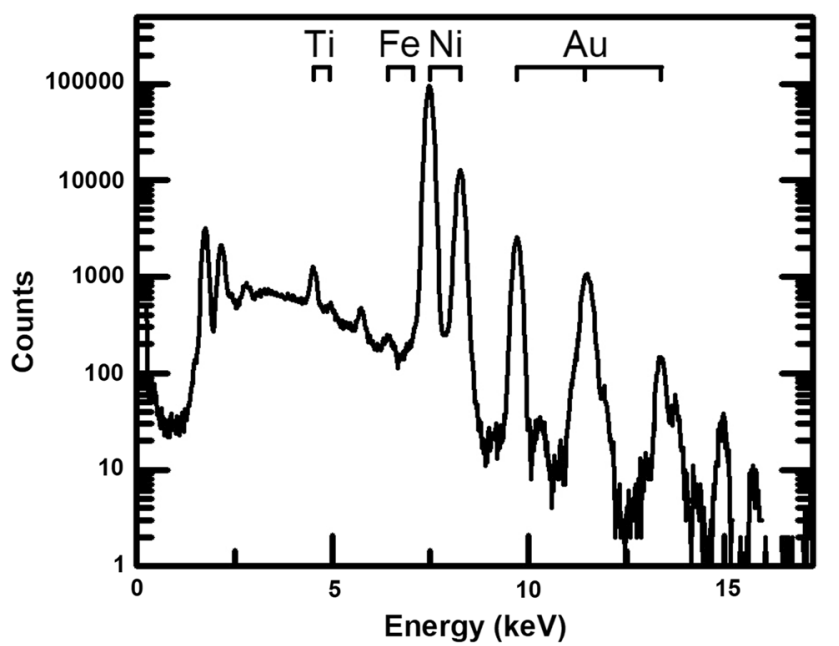

Springer 


\section{Results and discussion}

Figure 4 shows the ratio of the Fe determined by integrating CV measurements to the Fe determined by PIXE. The hypothesis underlying these measurements was that the PIXE method measures all the Fe in the sample, while the $\mathrm{CV}$ method only measures the active Fe in the sample, and therefore the ratio should be smaller than one. This is because the proton beam passes through the entire thickness of the sample and therefore PIXE measures the areal density of all of the Fe present in the sample. The ratios of these two measurements as seen in Fig. 4, confirms the initial hypothesis for a number of samples fabricated and tested.

Efficiency is defined by this ratio of active to total amounts of material. These ratios also can be converted to a specific charge capacity assuming a ratio of 1 corresponds to the theoretical capacity of $\mathrm{Na}_{2} \mathrm{NiFe}(\mathrm{CN})_{6}, 84.9 \mathrm{mAh} / \mathrm{g}$ [6], and that conversion is shown as a second vertical axis on the figure. The results demonstrate that there is an efficiency of approximately $40-90 \%$ of active to total Fe in a sample which corresponds to a specific capacity of about 34-76 mAh/g.

The results also demonstrate that even for the same procedure, sample to sample variation occurs and therefore doing such sample fabrication in a more controlled environment may enable more reproducible results. It is necessary to understand what variations are occurring and if they affect the percent efficiency of the sample. Reasons for this may depend on variation in sample creation such as sample smoothness, as well as possible kinetic differences that occur even when the same method for fabrication is used. Previous work with mixed metal PBAs has shown that increasing surface area is correlated with increasing measured charge storage [44]. Further research could evaluate if the efficiency of charge storage is also affected by the roughness of the sample.

To better understand the details of the charge exchange and study the kinetics of the charge storage properties of the PBA, CA analysis was performed on the samples. For an electroactive thin film, the integrated charge as a function of time is given by

$$
Q=Q_{\mathrm{f}}\left(1-\frac{8}{\pi^{2}} \exp \left(\frac{-\pi^{2} t}{\tau}\right)\right),
$$

where $Q_{\mathrm{f}}$ is the finite amount of charge stored in the film,

$$
\tau=\frac{4 d^{2}}{D}
$$

is the time constant for charge transfer within the film, $d$ is film thickness, and $D$ is the effective diffusion constant [45]. For the samples measured, instead of asymptotically approaching $Q_{f}$ as predicted by Eq. 5, the charge calculated from the CA scans on time scales of 60-300 s continued to increase linearly (Fig. 5). To account for this behavior, the theory was adapted to include a constant current term,

Fig. 4 The ratio of the Fe measured by the $\mathrm{CV}$ method to the Fe measured by the PIXE method for a number of samples. The range of the ratio of active atoms to total atoms varies between 40 and $90 \%$. The second vertical axis is the specific charge capacity assuming a ratio of 1 corresponds to the theoretical capacity of $\mathrm{Na}_{2} \mathrm{NiFe}(\mathrm{CN})_{6}$, $84.9 \mathrm{mAh} / \mathrm{g}$

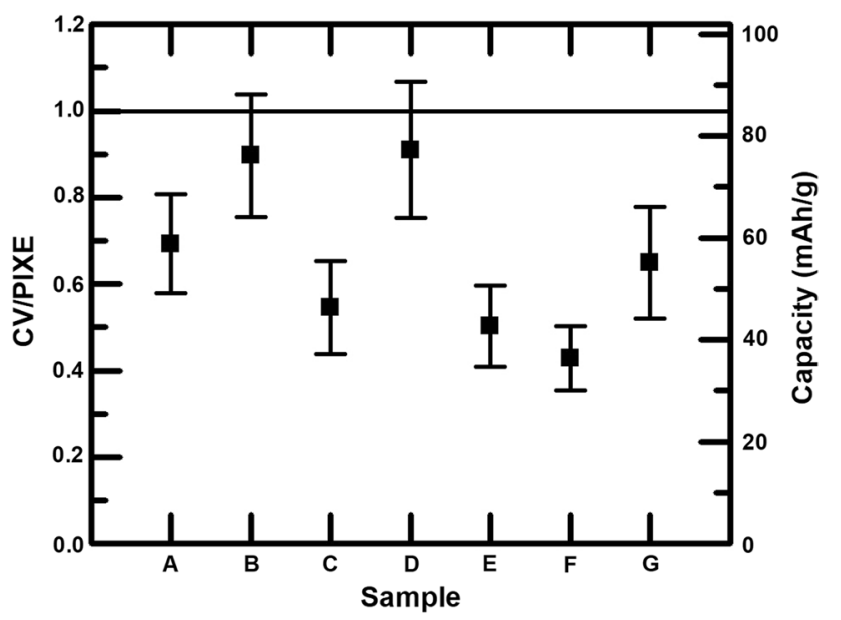


Fig. 5 Example integrated CA data for a Ni-HCF sample. The line is a fit to Eq. 7 with fit values of $Q_{f}=79 \pm 3 \mu \mathrm{C}$, $\tau=76 \pm 6 \mathrm{~s}, I_{c}=3.39 \pm 0.03 \mu$ A

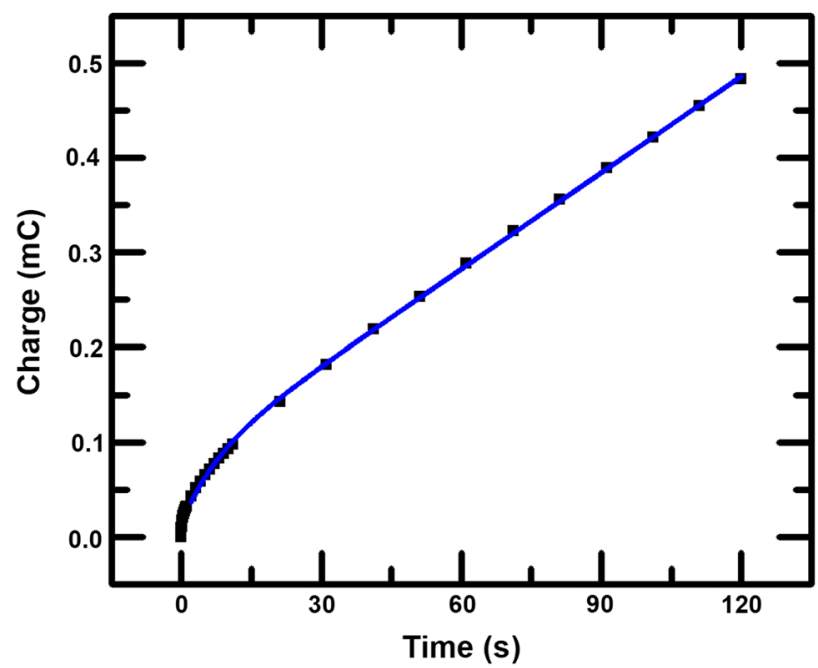

$$
Q=Q_{f}\left(1-\frac{8}{\pi^{2}} \exp \left(\frac{-\pi^{2} t}{\tau}\right)\right)+I_{c} t
$$

where $I_{c}$ is the constant current. The CA data was interpreted with the adapted equation. From these fits, values for $Q_{f}$, $I_{c^{\prime}}$ and $\tau$ were determined. Non-zero values of $I_{c}$ were observed for all of the samples, indicating the presence of an additional constant current reaction at $0.800 \mathrm{~V}$. By using Eq. 7 to interpret the CA data, $Q_{f}$ values do not include the effects of the constant current process. This is analogous to the background subtraction procedure used to interpret the CV data without the influence of the sloped background current. Therefore, in both cases, we only measure the charge storage of the Ni-HCF film and do not include any other additional effects.

Other researchers have also observed additional reactions occurring for PBAs in water. For example, Cordova and coworkers observed a linear current during a reductive CA step from $1.1 \mathrm{~V}$ to $0.5 \mathrm{~V}$ for a Prussian Blue film [46]. They attribute this to a cycle of chemical and electrochemical reactions that occur due to the catalytic oxidation of water during the previous oxidative step. Research planned in our lab includes testing PBAs in both aqueous and non-aqueous solutions. Comparing the aqueous and non-aqueous characterization of these samples will allow us to identify and explore these additional reactions.

Figure 6 shows the charge values from background subtracted CV data at various scan rates and the average of the $Q_{f}$ values which were determined from fitting several sets of integrated CA data to Eq. 7. Although the two methods are analogous, there is a discrepancy between the calculated charges. The CV charge values were calculated assuming the

Fig. 6 Charge as measured for a single sample using the integrated $\mathrm{CV}$ results and the fitted $Q_{f}$ values from the CA method. CA runs for this sample were averaged and are drawn as a dashed line with its minimum and maximum uncertainty as the dotted lines. The charge values measured from CV scans for slower scan rates are significantly higher than the charge values for higher scan rates

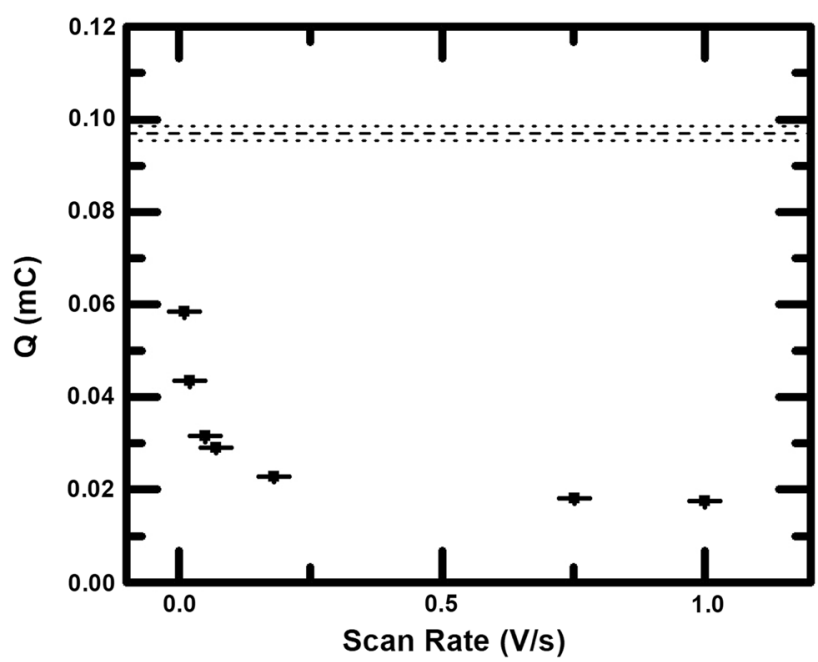


only reaction of interest was the oxidation of the Fe present in the PBA. Thus, this analysis reveals that the reactions of the PBA may be more complex than initially thought.

\section{Conclusion}

Fabricating Ni-HCF thin films with only electrochemical processes introduces a new method of production and study for PBAs. An original, non-destructive method for independently measuring the amount of Fe present in the PBA sample was developed. As a result, CV and PIXE measurements of the amount of Ni-HCF formed in a sample can be accurately analyzed and compared. This comparison method gives the measured specific capacity as a fraction of the theoretical capacity of the Ni-HCF. This now enables a metric with which PBA samples can be compared to typical or current battery technologies. Lastly, the disagreement between the CV and CA electrochemical measurements of the areal density of active Fe present in a sample requires further study. These results mean that charge storage properties may be dependent on the kinetics of the intercalating ions, leading to the difference between the CA and CV measurements. Another interpretation of the results is that Fe may not be the only substance oxidizing. This additional reaction would not be contributing to the observed peak but could be part of the background, boosting the charge capacity of the sample as measured by the CA method. Finally, the model selected could be insufficient for properly fitting the CA data, especially if there is an additional, finite reaction occurring.

Efforts are now under way to precisely determine the specific reactions that are responsible for the PBAs' charge storage. In addition, future work planned in our lab will adjust the Ni deposition step so that all of it is reacted to form PBA in the modification step. In this case, PIXE can be used to determine not only the Fe content in the material, but also the stoichiometry of the entire PBA film as fabricated.

We also plan to pursue methods that could be applied to these fabrication techniques in order to increase the efficiency of the PBA samples. One such method of interest is increasing the surface area of the sample. For this future work, the methods described here will enable accurate comparison of the efficiency of fabricated PBA samples to each other and to other current battery technologies.

Acknowledgements We acknowledge support from the Hope College Physics Department and the rest of the Surface Lab, including Amanda Rensmo, Brittany Devlin, Jacob Kelley, Forest Rulison, and Kameron Wilcox. We also acknowledge the tireless work of Dave Daugherty in keeping the accelerator maintained, constructing the Teflon cells used for testing, and the various other tasks that enabled these experiments to be possible.

Authors' contributions SJ: Investigation, Methodology, Formal Analysis, Visualization, Writing-Original Draft, Writing-Review and Editing. PDY: Supervision, Methodology, Formal Analysis, Writing-Review and Editing. JH: Project Administration, Funding Acquisition, Methodology, Formal Analysis, Writing-Review and Editing. All authors read and approved the final manuscript.

Funding This research was made possible by the United States National Science Foundation under NSF-RUI Grant No. DMR-1608327 and NSF-MRI/RUI Grant No. PHY-0319523.

Data availability The data generated for this experiment are available from the corresponding author upon request.

\section{Declarations}

Competing interests The authors declare no financial interests.

Open Access This article is licensed under a Creative Commons Attribution 4.0 International License, which permits use, sharing, adaptation, distribution and reproduction in any medium or format, as long as you give appropriate credit to the original author(s) and the source, provide a link to the Creative Commons licence, and indicate if changes were made. The images or other third party material in this article are included in the article's Creative Commons licence, unless indicated otherwise in a credit line to the material. If material is not included in the article's Creative Commons licence and your intended use is not permitted by statutory regulation or exceeds the permitted use, you will need to obtain permission directly from the copyright holder. To view a copy of this licence, visit http://creativecommons.org/licenses/by/4.0/. 


\section{References}

1. Karyakin AA. Prussian blue and its analogues: electrochemistry and analytical applications. Electroanalysis. 2001. 13(10):813. https://doi. org/10.1002/1521-4109(200106)13.

2. de Tacconi NR, Rajeshwar K, Lezna RO. Metal hexacyanoferrates: Electrosynthesis, in situ characterization, and applications. Chem Mater. 2003;15(16):3046. https://doi.org/10.1021/cm0341540.

3. Huggins RA. Review-A new class of high rate, long cycle life, aqueous electrolyte battery electrodes. J Electrochem Soc. 2017;164(1):A5031. https://doi.org/10.1149/2.0571701jes.

4. Ma F, Li Q, Wang T, Zhang H, Wu G. Energy storage materials derived from Prussian blue analogues. Sci Bull. 2017;62(5):358. https://doi. org/10.1016/j.scib.2017.01.030.

5. Paolella A, Faure C, Timoshevskii V, Marras S, Bertoni G, Guerfi A, Vijh A, Armand M, Zaghib K. A review on hexacyanoferrate-based materials for energy storage and smart windows: challenges and perspectives. J Mater Chem A. 2017;5(36):18919-32. https://doi. org/10.1039/C7TA05121B.

6. Wang B, Han Y, Wang X, Bahlawane N, Pan H, Yan M, Jiang Y. Prussian blue analogs for rechargeable batteries. iScience. $2018 ; 3: 110$. https://doi.org/10.1016/j.isci.2018.04.008.

7. Xing Z, Wang S, Yu A, Chen Z. Aqueous intercalation-type electrode materials for grid-level energy storage: Beyond the limits of lithium and sodium. Nano Energy. 2018;50:229. https://doi.org/10.1016/j.nanoen.2018.05.049.

8. Hurlbutt K, Wheeler S, Capone I, Pasta M. Prussian Blue Analogs as battery materials. Joule. 2018;2(10):1950. https://doi.org/10.1016/j. joule.2018.07.017.

9. Chen J, Wei L, Mahmood A, Pei Z, Zhou Z, Chen X, Chen Y. Prussian blue, its analogues and their derived materials for electrochemical energy storage and conversion. Energy Storage Mater. 2020;25:585. https://doi.org/10.1016/j.ensm.2019.09.024.

10. Malik MA, Kulesza PJ, Marassi R, Nobili F, Miecznikowski K, Zamponi S. Countercation intercalation and kinetics of charge transport during redox reactions of nickel hexacyanoferrate. Electrochim Acta. 2004;49(25):4253. https://doi.org/10.1016/j.electacta.2004.04. 021.

11. Moritomo Y, Takachi M, Kurihara Y, Matsuda T. Thin film electrodes of Prussian blue analogues with rapid Li+ intercalation. Appl Phy Exp . 2012. 15;5(4):041801. https://doi.org/10.1143/APEX.5.041801/pd.

12. Okubo M, Li CH, Talham DR. High rate sodium ion insertion into core-shell nanoparticles of Prussian blue analogues. Chem Commun. 2014;50(11):1353. https://doi.org/10.1039/C3CC47607C.

13. Li CH, Nanba Y, Asakura D, Okubo M, Talham DR. Li-ion and Na-ion insertion into size-controlled nickel hexacyanoferrate nanoparticles. RSC Adv. 2014;4(48):24955. https://doi.org/10.1039/C4RA03296A.

14. Shibata T, Moritomo Y. Ultrafast cation intercalation in nanoporous nickel hexacyanoferrate. Chem Commun. 2014;50(85):12941. https:// doi.org/10.1039/C4CC04564E.

15. Jayalakshmi M, Scholz F. Performance characteristics of zinc hexacyanoferrate/Prussian blue and copper hexacyanoferrate/Prussian blue solid state secondary cells. J Power Sources. 2000;91(2):217. https://doi.org/10.1016/S0378-7753(00)00475-4.

16. Okubo M, Asakura D, Mizuno Y, Kim JD, Mizokawa T, Kudo T, Honma I. Honma, Switching redox-active sites by valence tautomerism in Prussian blue analogues A x Mn y [Fe (CN) 6] $n$ H2O (A: K, Rb): Robust frameworks for reversible Li storage. J Phys Chem Lett. 2010;1(14):2063. https://doi.org/10.1021/jz100708b.

17. Wessells CD, Huggins RA, Cui Y. Copper hexacyanoferrate battery electrodes with long cycle life and high power. Nat Commun. $2011 ; 2: 550$. https://doi.org/10.1038/ncomms1563.

18. Wessells CD, McDowell MT, Peddada SV, Pasta M, Huggins RA, Cui Y. Tunable reaction potentials in open framework nanoparticle battery electrodes for grid-scale energy storage. ACS Nano. 2012;6(2):1688. https://doi.org/10.1021/nn204666v.

19. Wu X, Deng W, Qian J, Cao Y, Ai X, Yang H. Single-crystal FeFe (CN) 6 nanoparticles: a high capacity and high rate cathode for Na-ion batteries. J Mater Chem A. 2013;1(35):10130. https://doi.org/10.1039/c3ta12036h.

20. Krishnamoorthy K, Pazhamalai P, Sahoo S, Lim JH, Choi KH, Kim SJ. A high-energy aqueous sodium-ion capacitor with nickel hexacyanoferrate and graphene electrodes. ChemElectroChem. 2017;4(12):3302. https://doi.org/10.1002/celc.201700690.

21. Chen J, Huang K, Liu S. Insoluble metal hexacyanoferrates as supercapacitor electrodes. Electrochem Commun. 2008;10(12):1851. https:// doi.org/10.1016/j.elecom.2008.07.046.

22. Lu Y, Wang L, Cheng J, Goodenough JB. Prussian blue: a new framework of electrode materials for sodium batteries. Chem Commun. 2012;48(52):6544. https://doi.org/10.1039/c2cc31777j.

23. Mizuno Y, Okubo M, Asakura D, Saito T, Hosono E, Saito Y, Oh-ishi K, Kudo T, Zhou H. Impedance spectroscopic study on interfacial ion transfers in cyanide-bridged coordination polymer electrode with organic electrolyte. Electrochim Acta. 2012;63:139. https://doi.org/ 10.1016/j.electacta.2011.12.068.

24. Wang L, Lu Y, Liu J, Xu M, Cheng J, Zhang D, Goodenough JB. A superior low-cost cathode for a Na-lon battery. Angew Chem Int Ed. 2013;52(7):1964. https://doi.org/10.1002/anie.201206854.

25. Pasta M, Wessells CD, Liu N, Nelson J, McDowell MT, Huggins RA, Toney MF, Cui Y. Full open-framework batteries for stationary energy storage. Nat Commun. 2014;5:3007. https://doi.org/10.1038/ncomms4007.

26. You Y, Wu XL, Yin YX, Guo YG. High-quality Prussian blue crystals as superior cathode materials for room-temperature sodium-ion batteries. Energy Environ Sci. 2014;7(5):1643. https://doi.org/10.1039/c3ee44004d.

27. You Y, Yu X, Yin Y, Nam KW, Guo YG. Sodium iron hexacyanoferrate with high Na content as a Na-rich cathode material for Na-ion batteries. Nano Res. 2015;8(1):117. https://doi.org/10.1007/s12274-014-0588-7.

28. Wu X, Luo Y, Sun M, Qian J, Cao Y, Ai X, Yang H. Low-defect Prussian blue nanocubes as high capacity and long life cathodes for aqueous Na-ion batteries. Nano Energy. 2015;13:117. https://doi.org/10.1016/j.nanoen.2015.02.006.

29. Wu X, Wu C, Wei C, Hu L, Qian J, Cao Y, Ai X, Wang J, Yang H. Highly crystallized Na2CoFe(CN)6 with suppressed lattice defects as superior cathode material for sodium-ion batteries. Appl ACS Mater Interfaces. 2016;8(8):5393. https://doi.org/10.1021/acsami.5b12620. 
30. Tang Y, Li W, Feng P, Zhou M, Wang K, Wang Y, Zaghib K, Jiang K. High-performance manganese hexacyanoferrate with cubic structure as superior cathode material for sodium-ion batteries. Adv Funct Mater. 2020;30(10):1908754. https://doi.org/10.1002/adfm.201908754.

31. Bocarsly AB, Sinha S. Chemically-derivatized nickel surfaces: Synthesis of a new class of stable electrode interfaces. J Electroanal Chem Interfacial Electrochem. 1982;137(1):157. https://doi.org/10.1016/0022-0728(82)85075-4.

32. Bocarsly $A B$, Sinha $S$. Effects of surface structure on electrode charge transfer properties: Induction of ion selectivity at the chemically derivatized interface. J Electroanal Chem Interfacial Electrochem. 1982;140(1):167. https://doi.org/10.1016/0368-1874(82)85310-0.

33. Sinha S, Humphrey BD, Bocarsly AB. Reaction of nickel electrode surfaces with anionic metal-cyanide complexes: formation of precipitated surfaces. Inorg Chem. 1984;23(2):203. https://doi.org/10.1021/ic00170a018.

34. Humphrey BD, Sinha S, Bocarsly AB. Diffuse reflectance spectroelectrochemistry as a probe of the chemically derivatized electrode interface. The derivatized nickel electrode. J Phys Chem. 1984;88(4):736. https://doi.org/10.1021/j150648a024.

35. Sinha S, Humphrey BD, Fu E, Bocarsly AB. The coordination chemistry of chemically derivatized nickel surfaces generation of an electrochromic interface. J Electroanal Chem Interfacial Electrochem. 1984;162(1-2):351. https://doi.org/10.1016/S0022-0728(84)80178-3.

36. Amos LJ, Schmidt MH, Sinha S, Bocarsly AB. Overlayer-support interactions associated with the formation of a chemically modified interface: the nickel ferrocyanide derivatized nickel electrode. Langmuir. 1986;2(5):559. https://doi.org/10.1021/la00071a005.

37. Humphrey BD, Sinha S, Bocarsly AB. Mechanisms of charge transfer at the chemically derivatized interface: the Ni/[Nill(CN)Fell/III (CN)5(2/1-) system as an electrocatalyst. J Phys Chem. 1987;91(3):586. https://doi.org/10.1021/j100287a020.

38. Amos LJ, Duggal A, Mirsky EJ, Ragonesi P, Bocarsly AB, Fitzgerald-Bocarsly PA. Morphological variation at the $[\mathrm{NiFe}(\mathrm{CN}) 6](2-/-)$ derivatized nickel electrode: A technique for the evaluation of alkali cation containing solutions. Anal Chem. 1988;60(3):245. https://doi.org/10.1021/ ac00154a012.

39. Arbuckle GA, Chen Y, Hidalgo-Luangdilok C, Bocarsly AB. Electrochemical reactivity of ultra-thin cyanometallate films on electrode surfaces. Solid State lonics. 1989;32-33:(Part 2):941. https://doi.org/10.1016/0167-2738(89)90379-2.

40. Johansson S, Campbell JL, Malmqvist KG. Chronocoulometric Study of the Electrochemistry of Prussian Blue, Particle-induced X-ray emission spectrometry (PIXE). New York: Wiley; 1995.

41. Wozniak NR, Frey AA, Osterbur LW, Boman TS, Hampton JR. An electrochemical cell for the efficient turn around of wafer working electrodes. Rev Sci Instrum. 2010;81(3):034102. https://doi.org/10.1063/1.3360849.

42. Frey AA, Wozniak NR, Nagi TB, Keller MP, Lunderberg JM, Peaslee GF, DeYoung PA, Hampton JR. Analysis of electrodeposited nickel-iron alloy film composition using particle-induced X-Ray emission. Int J Electrochem. 2011;2011: https://doi.org/10.4061/2011/604395.

43. Maxwell JA, Teesdale WJ, Campbell JL. The Guelph PIXE software package II. Nucl Instrum Meth B. 1995;95(3):407. https://doi.org/10. 1016/0168-583X(94)00540-0.

44. Rensmo A, Hampton JR. Comparison of charge storage properties of Prussian Blue Analogues containing cobalt and copper. Metals. 2019;9(12):1343. https://doi.org/10.3390/met9121343.

45. Chambers JQ. Chronocoulometric determination of effective diffusion cofficients for charge transfer through thin electroactive polymer films. J Electroanal Chem Interfacial Electrochem. 1981;130:381. https://doi.org/10.1016/S0022-0728(81)80410-X.

46. Orellana M, Arriola P, Del Río R, Schrebler R, Cordova R, Scholz F, Kahlert H. Chronocoulometric study of the electrochemistry of Prussian Blue. J Phys Chem B. 2005;109(32):15483. https://doi.org/10.1021/jp051895a.

Publisher's Note Springer Nature remains neutral with regard to jurisdictional claims in published maps and institutional affiliations. 